\title{
The relationship between pelvic organ prolapse and short birth intervals in a rural area of Nepal
}

\author{
Rupa Singh ${ }^{1 *}$, Sandeep Mahat ${ }^{2}$, Sonam Singh ${ }^{3}$, Carolyn K. Nyamasege ${ }^{1}$ and Yukiko Wagatsuma ${ }^{4}$
}

\begin{abstract}
Background: Pelvic organ prolapse (POP) is one of the main contributors to reproductive health problems that affect women's quality of life. Previous studies have reported the risk factors and prevalence of POP. The aim of this study is to examine the association between POP and short birth intervals in a rural area of Nepal.

Methods: A cross-sectional study was conducted in Panchapuri municipality, located in Surkhet District of Karnali Province in Nepal. A questionnaire was used to collect information on POP, birth intervals, and other known confounding factors, such as age and parity. Multiple logistic regression analysis was used to examine the association between minimum birth intervals and POP.

Results: The study recruited 131 women. The prevalence of POP was $29.8 \%$. The mean (SD) of maternal age was 32.3 (0.7) years. The median parity was 2 , with a range of 2-6 children. More than half (64.9\%) of the women reported a minimum birth interval of less than 2 years. Maternal age at birth, minimum birth interval, parity, and latest birth interval were significantly associated with POP in univariate analyses. After adjusting for the potential confounding factors such as age and occupation, the minimum birth interval was significantly associated with POP $[A O R=3.08,95 \%$ Cl 1.04-9.19].

Conclusion: The prevalence of POP was high in this rural area of Nepal. Age, parity, occupation, and minimum birth interval were significantly associated with POP.
\end{abstract}

Keywords: Reproductive health, Pelvic organ prolapse, Birth interval, Nepal

\section{Background}

Pelvic organ prolapses (POP) is the bulging or protrusion of the pelvic organs, including the bladder, rectum, small bowel, and uterus and their associated vaginal segments, into or through the vagina [1]. It is a disorder commonly seen in older women. The prevalence of POP has been reported as $9 \%$ in the world in the global burden of diseases study in 2012 [2]. Whereas other studies from various countries reported the ranges from 2.9 to $41.1 \%$ [3-6]. It is difficult to obtain consistent prevalence statistics

\footnotetext{
* Correspondence: sadgul75@gmail.com

${ }^{1}$ Graduate School of Comprehensive Human Sciences, University of Tsukuba,

1-1-1 Tennodai, Tsukuba, Ibaraki 305-8575, Japan

Full list of author information is available at the end of the article
}

because POP diagnosis (based on symptoms, physical examination, or surgery) differs across studies $[5,6]$.

While POP is generally considered a postmenopausal disease, considerable attention has been given to the disease burden among women of reproductive age in less developed countries $[7,8]$. One study reported a POP prevalence rate of $37 \%$ in Nepal [9]. The western region of Nepal, including Panchapuri Province, reported to have a higher risk of POP [9]. In low-income countries, women are prone to believe or are made to believe that reproductive health problems such as falling of the uterus are simply a woman's fate $[10,11]$. Poor reproductive health among women is a major public health problem in many developing countries, including Nepal. Delivering at home for the first-time pregnancy is

(c) The Author(s). 2021 Open Access This article is licensed under a Creative Commons Attribution 4.0 International License, which permits use, sharing, adaptation, distribution and reproduction in any medium or format, as long as you give appropriate credit to the original author(s) and the source, provide a link to the Creative Commons licence, and indicate if changes were made. The images or other third party material in this article are included in the article's Creative Commons licence, unless indicated otherwise in a credit line to the material. If material is not included in the article's Creative Commons licence and your intended use is not permitted by statutory regulation or exceeds the permitted use, you will need to obtain permission directly from the copyright holder. To view a copy of this licence, visit http://creativecommons.org/licenses/by/4.0/. 
another obstetric factor associated with an increased risk of POP. Besides, home delivery in a low-income setting is also linked to an increased risk of poor maternal and perinatal outcomes [10].

Closely spaced deliveries and multiple births may have long-term implications for women's reproductive health [12]. The more vaginal births women have, the greater the possibility of POP [13]. Short birth intervals are still prevalent and mostly unplanned in the most part of the world [14]. In Nepal, 21\% of child is born less than 2 years of interval. However, it differs by zone and region [15]. Those who have suffered a pregnancy or child loss are more likely to replace that pregnancy/child and hence the interval between births is short. Knowledge of birth spacing and its underlying characteristics, such as illiteracy, early marriage, lack of family planning, and poverty, are relevant to understanding reproductive patterns and fertility behavior [16]. Epidemiological studies of POP incidence and remission are scarce [17]. Valid information on the prevalence of POP is crucial for gynecological and reproductive health care planning [4].

Many researchers reported about the relationship between birth spacing and maternal and child health [12, 18]. Women with short birth intervals are associated with higher maternal mortality [19]. However, limited studies have been done on the relationship between short birth interval and the occurrence of POP [20, 21]. Therefore, preventive efforts can be suggested if the interval between each birth relates to the occurrence of POP. This study aimed to examine the association of short birth intervals of less than 2 years and the occurrence of $\mathrm{POP}$ among reproductive age women in a rural area of Nepal.

\section{Methods}

\section{Study area and population}

This study was conducted in Panchapuri municipality, located in Surkhet District of Karnali Province in Nepal. Surkhet is located nearly $580 \mathrm{~km}$ west of Kathmandu, the capital city of Nepal. The total population is 32,231, and the municipality covers an area of $329.9 \mathrm{~km}^{2}$ [22]. This area was chosen because of its high prevalence of POP $[9,11]$. Panchapuri municipality has only one primary health care centers (PHCCs), called Salkot, and 4 other health posts. Data collection was conducted in five villages where PHCCs and health posts exist. The data collection period was from February to April 2019. Married women aged between 18 and 49 with a history of at least two deliveries were asked to participate in the study. Approximately equal numbers of women were recruited from each of the four health post catchment areas. If hysterectomy was conducted due to POP, such cases were also included. The woman who did not sign the consent form was excluded.

\section{Study design}

A cross-sectional study was conducted. A semistructured questionnaire was used to collect the data through a face-to-face interview. Eight interviewers, including two staff nurses and six female community health volunteers (FCHVs), assisted with the data collection. The interviewers were trained on the procedures for administering the questionnaire and on the symptoms and treatment of POP.

\section{Information included in the questionnaire}

The study participants may not be well informed on the medical manifestations of POP. Therefore, the interviewer used a language that would be understandable to the lay person when asking questions, e.g., "Do you feel a dragging lump coming down in or outside the vagina?" Women's recognition of the presence of this condition was considered the presence of POP. Socio-economic and demographic information of the households and caregivers were also collected. The questionnaire for this study was developed in reference to a standardized questionnaire regarding POP signs, symptoms, risk factors, treatment options, and preventive measures [23]. The Prolapse Quality of Life Questionnaire (P- QOL) was used to evaluate POP symptoms and quality of life [24]. Moreover, the tools were modified after being translated into Nepali language and were pretested in Surkhet district of Nepal before use by trained interviewers. Socioeconomic and demographic information on the households was included in section I, whereas questions related to POP and health service-related information were included in sections II and III (supplementary material S1).

\section{Narrative study of self-reported reasons for POP}

We conducted a narrative study was conducted by interviewing the participants regarding their self-reported reasons for POP. Women used many different words to describe POP. The WHO subgroup sample questions such as "do you feel anything coming out of your vagina?", "Do you have a feeling of heaviness?", and "is it uncomfortable down below?" were asked to elicit the presence of POP. These questions from the WHO can identify $80-90 \%$ of moderate and severe POP. The study subjects were encouraged to freely share their experiences related to reproductive issues during and after pregnancy. Most common feedbacks from mothers were selected and reported in the results. The interviewers were asked to take more detailed notes when there was a POP case. Voices were recorded and used later for the qualitative study. For almost all cases, women spent about 30-40 min giving a more in-depth explanation. 


\section{Sample size calculation}

We calculated the sample size based on testing the hypothesis of the differences in POP prevalence between the group with a birth interval of $<2$ years and the group with a birth interval of $\geq 2$ years. It was assumed that the group with a birth interval of $<2$ years has a POP prevalence of $30 \%$ from the previous study [25] while the other group a prevalence of $15 \%$ [26]. The required sample size was calculated as 126 , with a $5 \%$ attrition rate to account for missing data, a power of 0.80 , and an alpha value of 0.05 based on a 2 -sided test [27].

\section{Study variables}

Minimum birth interval and immediately preceding birth interval were the three predictor variables used in this study while POP prevalence was the outcome. Age, parity, occupation, and education were used as co-variates as guided by existing literatures $[8,9]$. The minimum birth interval was defined as the minimum length (years) in any birth intervals from each woman. A cutoff value of 2 years was used since WHO recommends a healthy pregnancy interval of at least 2 years (24 months), whereas immediately preceding birth interval was defined as the most recent birth interval.

\section{Statistical analysis}

Descriptive analysis was performed to determine the frequencies and percentages of the characteristics of the study participants (education, occupation, ethnicity, monthly income, age at first childbirth, contraceptive use, place of delivery). Age and parity were analyzed as categorical variables. Education was categorized as none, primary, and secondary and above. Occupation was also categorized into three groups: business, commercial farm, and housewife. Univariate logistic regression was used to test the association between the selected variables and POP. Multivariate logistic regression analysis was then performed to examine the association between POP and the minimum birth interval with the adjustment of co-variates. Multicollinearity of the variables included in the analysis was examined. A $p$ value of $<0.05$ was considered statistically significant. All analyses were conducted with IBM SPSS version 24. Codes and themes were not created for qualitative data because of the limited responses, only from a few of the women presenting with POP. Consequently, we reported some of the narratives from the women presenting with POP.

\section{Ethical considerations}

This study was reviewed and approved by the Ethical Committee of the Faculty of Medicine, University of Tsukuba, and the Nepal Health Research Council (NHRC). To minimize discomfort and inconvenience, the survey team explained the objectives of the study in a nonthreatening and culturally relevant manner. The participants were given an opportunity to ask questions and to decline participation freely. Women provided a written informed consent were enrolled in the study. Collected data was verified and entered into a secure database with restricted access to maintain confidentiality.

\section{Results}

A total of 131 mothers from various village development committees (VDCs) in Panchapuri municipality in Surkhet, western Nepal, were interviewed. The general characteristics of the study participants are presented in Table 1. The mean (SD) maternal age was $32.3(0.7)$ years. The median parity was 2 , with a range of $2-6$ children. There were no women aged below 20 years even though we planned to interview the targeted age group of 18 to 49 . Hence, the age was categorized above 20

Table 1 General characteristics of the study subjects $(N=131)$

\begin{tabular}{|c|c|c|}
\hline Characteristics & $N$ & $\%$ \\
\hline Age, years (mean $\pm S D$ ) & $32.27 \pm 6.91$ & \\
\hline \multicolumn{3}{|l|}{ Education } \\
\hline None & 86 & 65.6 \\
\hline Primary & 15 & 11.5 \\
\hline Secondary and above & 30 & 22.9 \\
\hline \multicolumn{3}{|l|}{ Occupation } \\
\hline Business & 48 & 36.6 \\
\hline Commercial farm & 49 & 37.4 \\
\hline Housewife & 34 & 26.0 \\
\hline \multicolumn{3}{|l|}{ Ethnicity } \\
\hline Brahmin & 35 & 26.7 \\
\hline Chhetri & 25 & 19.1 \\
\hline Dalit & 63 & 48.1 \\
\hline Other & 8 & 6.1 \\
\hline \multicolumn{3}{|c|}{ Monthly income, Nepalese. Rs. } \\
\hline$>5000$ & 21 & 16.0 \\
\hline $5000-$ & 28 & 21.4 \\
\hline $10000-$ & 19 & 14.5 \\
\hline $15000-$ & 21 & 16.0 \\
\hline$\geq 20000$ & 42 & 32.1 \\
\hline \multicolumn{3}{|c|}{ Age at first childbirth, years } \\
\hline$\geq 20$ & 101 & 77.1 \\
\hline$<20$ & 30 & 22.9 \\
\hline \multicolumn{3}{|l|}{ Contraceptive use } \\
\hline Yes & 76 & 58.0 \\
\hline No & 55 & 42.0 \\
\hline \multicolumn{3}{|l|}{ Place of delivery } \\
\hline Home & 61 & 46.6 \\
\hline Health facility & 70 & 53.4 \\
\hline
\end{tabular}


Table 2 Univariate logistic regression analysis for pelvic organ prolapse $(N=131)$

\begin{tabular}{|c|c|c|c|c|}
\hline Variables & POP $n(\%)$ & Non-POP $n(\%)$ & OR $[95 \% \mathrm{Cl}]^{\mathrm{a}}$ & $p$ value \\
\hline \multicolumn{5}{|c|}{ Minimum birth interval } \\
\hline$\geq 2$ years & $7(15.2)$ & $39(84.8)$ & Ref. & \\
\hline$<2$ years & $32(37.6)$ & $53(62.4)$ & $3.36[1.35,8.41]$ & 0.009 \\
\hline \multicolumn{5}{|c|}{ Immediately preceding birth interval } \\
\hline$\geq 2$ years & $12(18.8)$ & $52(81.2)$ & Ref. & \\
\hline$<2$ years & $27(40.3)$ & $40(59.7)$ & $2.93[1.32,6.48]$ & 0.008 \\
\hline \multicolumn{5}{|l|}{ Age, years } \\
\hline $20-29$ & $3(6.1)$ & $46(93.9)$ & Ref. & \\
\hline $30-39$ & $19(34.5)$ & $36(65.5)$ & $8.09[2.22,29.49]$ & 0.002 \\
\hline $40-49$ & $17(63.0)$ & $10(37.0)$ & $26.07[6.39,106.24]$ & $<0.001$ \\
\hline \multicolumn{5}{|l|}{ Parity } \\
\hline 2 & $10(25.6)$ & $58(63)$ & Ref. & \\
\hline 3 & $11(28.2)$ & $28(30.4)$ & $2.28[0.87,5.99]$ & 0.095 \\
\hline$\geq 4$ & $18(46.2)$ & $6(6.6)$ & $17.40[5.55,54.51]$ & $<0.001$ \\
\hline \multicolumn{5}{|l|}{ Occupation } \\
\hline Business & $9(23.1)$ & 39 (42.4) & Ref. & 0.494 \\
\hline Commercial farm & $12(30.8)$ & $37(40.2)$ & $1.41[0.53,3.72]$ & 0.002 \\
\hline Housewife & $18(46.1)$ & $16(17.4)$ & $4.88[1.81,13.11]$ & \\
\hline
\end{tabular}

${ }^{\mathrm{a}} \mathrm{OR}=[95 \% \mathrm{Cl}]$ Odds ratio, $\mathrm{Cl}$ Confidence interval, Ref. Reference category

years old in Table 1, 2, and 3. The majority (65.6\%) of the women had never been to school. Only $22.9 \%$ of the women had secondary and above level of education. More than half of the participants (51.9\%) had at least 2 children. A short birth interval of less than 2 years was reported by $64.9 \%$ of the women. Approximately half of the women $(52.7 \%)$ had worked more than usual during pregnancy, while $16.8 \%$ had worked less. Moreover, $89.3 \%$ of them stated that they visit public health

Table 3 Multivariable logistic regression analysis for pelvic organ prolapse $(N=131)$

\begin{tabular}{|c|c|c|}
\hline Variable categories & AOR $[95 \% \mathrm{Cl}]^{\mathrm{a}}$ & $p$ value \\
\hline \multicolumn{3}{|c|}{ Minimum birth interval } \\
\hline$\geq 2$ years & Ref. & \\
\hline$<2$ years & $3.08[1.04,9.19]$ & 0.043 \\
\hline \multicolumn{3}{|l|}{ Occupation } \\
\hline Business & Ref. & \\
\hline Commercial farm & $1.31[0.43,3.99]$ & 0.632 \\
\hline Housewife & $4.04[1.27,12.8]$ & 0.018 \\
\hline \multicolumn{3}{|l|}{ Age, years } \\
\hline $20-29$ & Ref. & \\
\hline $30-39$ & $6.77[1.79,25.66]$ & 0.005 \\
\hline $40-49$ & $15.60[3.61,67.41]$ & $<0.001$ \\
\hline
\end{tabular}

facilities for treatment. Among those with POP, 76.9\% were satisfied with the prolapse treatment that they received at health facilities.

Table 2 shows the univariate analysis for POP with selected variables. The minimum birth interval less than 2 years showed higher prevalence of POP $(\mathrm{OR}=3.36,95 \%$ CI 1.35-8.41). Moreover, immediately preceding birth interval had also a significant relationship with POP. Women with the latest interval of less than 2 years were almost 3 times more likely to experience POP than women with an interval longer than 2 years $(\mathrm{OR}=2.93$, 95\% CI 1.32-6.48). Age, parity and occupation showed a significant association with POP. Education level and physical work during pregnancy and average birth interval were not associated with POP.

Table 3 presents the results of the multivariable logistic regression analysis for POP where we tested the relationship of short birth interval and POP. Since age and parity were highly correlated, we adjusted for age and occupation in Table 3. After adjusting for age and occupation, the minimum birth interval was significantly associated with POP (AOR $=3.08,95 \%$ CI 1.04-9.19). The likelihood of POP was higher among housewives (AOR $=4.04,95 \%$ CI $1.27-12.8)$ than among women in the business group. The likelihood of POP was higher among women aged $30-39$ years $(\mathrm{AOR}=6.77,95 \% \mathrm{CI}$ 1.79-25.66) and $40-49$ years $(\mathrm{AOR}=15.60,95 \% \mathrm{CI}$ $3.61-67.41)$ than those aged $20-29$ years. 


\section{Self-reported reasons for POP}

Among the 131 participants, 39 had POP. Each of them had their own story about the condition. A 45-year-old woman explained how she was coping with POP as follows: "I felt something was coming out and blocking the opening of the vagina. I felt it was increasing while carrying heavy loads (water, firewood) and while washing or cleaning in a squatting position."

Out of the 131 women, fifty-four had complications during or after their pregnancies, such as prolonged labor or heavy bleeding with or without retained placenta. A 42-year-old woman described her past experience as follows: "During the first delivery, I faced 5 days and nights of labor pain and I was shifted from the local health post to a primary health care center for further procedures. At that time everything was gone, a total tear of the pelvic floor during the second pregnancy, and I had a hemorrhoid problem. It was so painful."

Among those with POP, 30 out of 39 women were satisfied with the treatment that they were receiving from public health facilities. The treatments included applying ring pessaries, taking medicines per the advice of medical experts, undergoing surgery, and performing pelvic floor exercises.

Likewise, a doctor said, “As a medical doctor, I don't think prolapse is a medical problem. If it were, it would have ended with surgical intervention. But women here continue to suffer even after surgery. I think prevention, awareness and removing risk factors can solve the problem in the long run. Although through this camp we will do surgeries for so many women, but there won't be postsurgical care or, if there is, we cannot guarantee that all the women here who had surgery will be there for the postsurgical care later, and these women have to walk for several hours to return home after this surgery."

Similarly, most of the women seem to be influenced with patriarchal norm pressure to have a male child and go through repeated pregnancies to do so, resulting many pregnancies without proper birth spacing. A 41year- old woman says, "I had to do all the household chores and agricultural work along with looking after my in-laws and, five children. 4 daughters and then a son. My husband is working abroad. I couldn't rest properly after giving birth to each child."

Referral and curative health services are poor despite improvements in primary and preventive health. However, locals are happy that they can obtain access to at least those limited health resources. It was also discovered that almost all the women from the surrounding area gathered for the free health checkup camp, which was held in Panchapuri municipality in February 2019. Women of different age groups, from the young to the elderly, participated in this forum and discussed their health problems without any reluctance, which was unexpected. They remained aware of reproductive health issues and were happy to share their feelings. The UNFPA reports that $80 \%$ of the women who went through surgery for uterine prolapse say they lost hope in life and hide their problems within themselves. However, in this study, women were not shy. Several participants revealed that they got information from female community health volunteers (FCHVs) during mothers' group meetings, where information was provided to local women on maternal and child health issues.

\section{Discussion}

This study was designed to assess the effect of birth spacing on the prevalence of POP. The findings show that the minimum birth interval was significantly associated with POP. This was the first epidemiological study conducted in Nepal with a focus on short birth interval and prevalence of POP. Although WHO has recommended a healthy pregnancy interval of at least 2 years (24 months), a majority of the women in this study reported the short birth interval of less than 2 years. Similarly, there are many countries reporting high percentages of pregnancies occurring within 24 months: Uttar Pradesh, India (30\%) [28], Pakistan (60\%) [29], and Kenya (50\%) [30]. If a woman has more than one child and the birth interval between the two children is short, it may result in a higher risk of POP. Short interpregnancy interval increases risk for uterine rupture and other major morbidities [18]. Closely spaced and multiple births may have adverse long-term implications for women's health [12]. Frequent conception, giving birth to many children, and lack of access to skilled attendants are also the main causes of POP [31]. A previous study by Bonetti et al. reported that 18 out of 32 women mentioned frequent childbearing as one of the perceived causes of POP [11].

The findings of this study indicate that POP is highly prevalent among women of reproductive age in Nepal. In this cross-sectional study, the prevalence of POP was found to be $29.8 \%$ which is relatively high compared to the previous study in Nepal which was found to be $10 \%$ [32], while another questionnaire-based study from Bangladesh reported the prevalence as $15.6 \%$ [33]. Even much higher prevalence of $64.6 \%$ was found from a recent study in Tanzania [34].

Our findings also showed that the prevalence of POP increases with age. This agrees with previous studies $[8$, $31,35]$. Notably most of the participants in this study were illiterate or had a lower level of education. Very few of them had a secondary- or college-level education. One of the previous studies reported that illiterate women have almost double the number of childbirths without proper birth spacing in Nepal [16]. In rural Nepal, women perform heavy physical work irrespective of their health condition. Our results agreed with the 
finding by Chiaffarino et al., which showed that housewives involved in heavy physical work were at increased risk of POP [36].

Nepal has made remarkable progress in improving maternal health. It is currently on track to meet the Sustainable Development Goal number 3 to ensure healthy lives and wellbeing for women. The total fertility rate (TFR) of women aged 15-49 declined from 4.1 in 2000 to 2.3 in 2016 according to the Ministry of Health of Nepal [37]. Even though this progress has been realized, the unique social and cultural practices in some rural areas of Nepal encourage women to bear many children at a young age and in a short span of time. This results in many pregnancies at brief intervals, which may significantly affect maternal health $[38,39]$. For example, Nepalese women giving birth to a female child tends to have a shorter birth interval and use a shorter acting contraceptive in order not to wait too long to get a male child $[11,36,40,41]$. Similarly, women living in rural areas may perform heavy physical work immediately after conceiving, irrespective of their health condition. Early marriage, early pregnancy, unassisted home delivery, lack of health facilities, and an unwillingness to seek health care during pregnancy and short birth interval due to various religious and social taboos are the major contributory factors [16, 32]. If women have so many children within a short interval, they cannot rest and work properly, and their children may have inadequate nutrition. In addition, they cannot give proper care equally to all the children [31].

\section{Limitations of the study}

One study limitation was the small sample size. Due to the limited number of cases, we recommended that similar study should be conducted using a larger sample size. This study was performed in only one municipality in mid-western Nepal, which may limit generalization to the whole of Nepal.

\section{Conclusion}

This study was unique in performing quantitative and qualitative research on the effect of short birth intervals on POP. The short birth interval was significantly associated with POP in a rural area of Nepal. Further studies are required to confirm the association.

\section{Supplementary Information}

The online version contains supplementary material available at https://doi. org/10.1186/s41182-021-00298-z.

Additional file 1: Supplementary material S1. Pelvic organ prolapse questionnaire 2019

\section{Abbreviations}

POP: Pelvic organ prolapse; PFD: Pelvic floor disorder; WHO: World Health Organization; COPD: Chronic obstructive pulmonary disease; SPSS: Statistical Package for the Social Sciences; OR: Odd ratios; Cl: Confidence interval; OB/ GYN: Obstetrician/gynecologist; TFR: Total fertility rate; $\mathrm{MOH}$ : Ministry of Heath; VDC: Village development committee; PHCC: Primary health care center; HP: Health post; UNFPA: United Nations Population Fund; VH: Vaginal hysterectomy; FCHVs: Female community health volunteers; RA: Research assistant

\section{Acknowledgements}

This study was conducted in collaboration with the University of Tsukuba and the Surkhet PHCs. We are thankful to Dr. Sandeep and Dr. Sonam for providing technical medical assistance throughout the field work. Sincere thanks to the generous support team, including the medical experts, FCHVs, and RAs. Finally, earnest thanks to all the women for their kind participation.

\section{Authors' contributions}

YW, CN, SS, SM, and RS contributed to the conceptualization and methodology. RS contributed to the analysis, investigation, resources, visualization, and writing. YW and CN contributed to the writing, reviewing, and editing. All authors read and approved the final manuscript.

\section{Funding}

This research received no external funding.

\section{Availability of data and materials}

The datasets analyzed during the current study are available from the corresponding author on reasonable request.

\section{Ethics approval and consent to participate}

This study was reviewed and approved by the Ethical Committee of the Faculty of Medicine, University of Tsukuba, and the Nepal Health Research Council (NHRC). To minimize discomfort and inconvenience, the survey team explained the objectives of the study in a nonthreatening and culturally relevant manner. The participants were given an opportunity to ask questions and to decline participation freely. Women provided a written informed consent were enrolled in the study. Collected data was verified and entered into a secure database with restricted access to maintain confidentiality.

\section{Consent for publication}

Not applicable

\section{Competing interests}

The authors declare that they have no competing interests.

\section{Author details}

${ }^{1}$ Graduate School of Comprehensive Human Sciences, University of Tsukuba, 1-1-1 Tennodai, Tsukuba, Ibaraki 305-8575, Japan. ${ }^{2}$ Resident Medical Officer, Department of Radiology, Bir Hospital, Kathmandu, Nepal. ${ }^{3}$ Medical Officer at Birendra Sainik Hospital, Chauni, Kathmandu, Nepal. ${ }^{4}$ Faculty of Medicine,

Department of Clinical Trials and Clinical Epidemiology, University of

Tsukuba, 1-1-1 Tennodai, Tsukuba, Ibaraki 305-8575, Japan.

Received: 12 October 2020 Accepted: 7 January 2021

Published online: 15 January 2021

References

1. Berek JS, Adashi EY, Hillard PA, Rinehart RD, Adashi EY, Berek \& Novak's Gynecology. Novak's GYNECOLOGY. 14th Editi. Richter H.E, Varner R.E, Berek \& Novak's Gynecology Jones HW, editors. 12th edition. Stanford: Lippincott Williams and Wilkins; 2007. p. 897-898.

2. Vos T, Flaxman AD, Naghavi M, Lozano R, Michaud C, Ezzati M, et al. Years lived with disability (YLDs) for 1160 sequelae of 289 diseases and injuries 1990-2010: a systematic analysis for the global burden of disease study 2010. Lancet. 2012:380:2163-96.

3. Hendrix SL, Clark A, Nygaard I, Aragaki A, Barnabei V, McTiernan A. Pelvic organ prolapse in the Women's health initiative: gravity and gravidity. Am J Obstet Gynecol. 2002;186:1160-6. 
4. Tegerstedt G, Maehle-Schmidt M, Nyrén O, Hammarström M. Prevalence of symptomatic pelvic organ prolapse in a Swedish population. Int Urogynecol J Pelvic Floor Dysfunct. 2005;16:497-503.

5. Rortveit G, Brown JS, Thom DH, Van Den Eeden SK, Creasman JM, Subak LL. Symptomatic pelvic organ prolapse: prevalence and risk factors in a populationbased, racially diverse cohort. Obstet Gynecol. 2007;109:1396-403.

6. Nygaard I, Barber MD, Burgio KL, et al. Prevalence of symptomatic pelvic floor disorders in US women. JAMA. 2008;300:1311-6.

7. Walker GJ, Gunasekera P. Pelvic organ prolapse and incontinence in developing countries: review of prevalence and risk factors. Int Urogynecol J. 2011;22:127-35.

8. Tinelli A, Malvasi A, Rahimi S, et al. Age-related pelvic floor modifications and prolapse risk factors in postmenopausal women. Menopause. 2010;17: 204-12.

9. Thapa S, Angdembe M, Chauhan D, Joshi R. Determinants of pelvic organ prolapse among the women of the western part of Nepal: a case-control study. J Obstet Gynaecol Res. 2014;40:515-20.

10. Pradhan A, Suvedi BK, Barnett S, Sharma SK, Puri M, Poudel P. Nepal maternal mortality and morbidity survey 2008/2009. Kathmandu: Government of Nepal, Ministry of Health and Population, Department of Health Services, Family Health Division; 2010.

11. Bonetti TR, Erpelding A, Pathak LR. Listening to "felt needs": investigating genital prolapse in western Nepal. Reprod Health Matters. 2004;12:166-75.

12. Grundy $E$, Kravdal $\varnothing$. Do short birth intervals have long-term implications for parental health? Results from analyses of complete cohort Norwegian register data. J Epidemiol Community Health. 2014;6810:958-64.

13. Memon HU, Handa VL. Vaginal childbirth and pelvic floor disorders. Womens Health (Lond). 2013;9:265-77.

14. Royce RA. Birth spacing--the long and short of it. JAMA. 2006;295:1837-8.

15. Ministry of Health and Population. Nepal demographic and health survey. Kathmandu: Ministry of Health and Population, New ERA, and ICF International, Calverton, Maryland; 2011.

16. Adhikari R. Demographic, socio-economic, and cultural factors affecting fertility differentials in Nepal. BMC Pregnancy Childbirth. 2010;10:19.

17. Barber MD. Pelvic organ prolapse. BMJ. 2016;354:i3853.

18. Conde-Agudelo A, Rosas-Bermudez A, Castaño F, Norton MH. Effects of birth spacing on maternal, perinatal, infant, and child health: a systematic review of causal mechanisms. Stud Fam Plann. 2012;43:93-114. https://doi. org/10.1111/j.1728-4465.2012.00308.x.

19. Schummers L, Hutcheon JA, Hernandez-Diaz S, Williams PL, Hacker MR, VanderWeele TJ, et al. Association of short interpregnancy interval with pregnancy outcomes according to maternal age. JAMA Intern Med. 2018; 178:1661-70. https://doi.org/10.1001/jamainternmed.2018.4696.

20. Panta PP, Phuyal S, Sharma D, Amgain K. Factors affecting uterine prolapse among females of 20-35 years on semi-urban area of Kathmandu district. J Karnali Acad Health Sci. 2018;1(3):14-9.

21. Joseph N, Krishnan C, Reddy BA, Adnan NA, Han LM, Min YJ. Clinical profile of uterine prolapse cases in South India. J Obstet Gynaecol India. 2016;66: 428-34. https://doi.org/10.1007/s13224-015-0783-9.

22. Central Bureau of Statistics Government of Nepal. National Population and Housing Census 2011 (National Report) Government of Nepal. Good Med Pract. 2012;01:40-41. NPHC 2011.

23. Shah AD, Massagli MP, Kohli N, Rajan SS, Braaten KP, Hoyte L. A reliable, valid instrument to assess patient knowledge about urinary incontinence and pelvic organ prolapse. Int Urogynecol J Pelvic Floor Dysfunct. 2008;19: 1283-9. https://doi.org/10.1007/s00192-008-0631-x.

24. Digesu GA, Khullar V, Cardozo L, Robinson D, Salvatore S. P-QOL: a validated questionnaire to assess the symptoms and quality of life of women with urogenital prolapse. Int Urogynecol J Pelvic Floor Dysfunct. 2005;16:17681discussion 181. https://doi.org/10.1007/s00192-004-1225-X.

25. Radl CM, Rajwar R, Aro AR. Uterine prolapse prevention in eastern Nepal: the perspectives of women and health care professionals. Int J Womens Health. 2012;4:373

26. WHO. Report of a WHO technical consultation on birth spacing. Geneva: World Health Organization; 2007.

27. Pagano M, Gauvreau K. Principles of biostatistics. Duxbury: Thomson Learning; Second Edi. Boston, Massachusetts; p. 331-2.

28. MCHIP. Family planning needs during the extended postpartum period in Uttar Pradesh, India; 2008.

29. MCHIP. Family planning needs during the first two years postpartum in Pakistan. Further analysis of DHS Pakistan; 2007.
30. MCHIP. Family planning needs during the first two years postpartum in Kenya; 2008.

31. Bodner-Adler B, Shrivastava C, Bodner K. Risk factors for uterine prolapse in Nepal. Int Urogynecol J Pelvic Floor Dysfunct. 2007:18:1343-6.

32. Gurung G, Rana A, Amatya A, Bista K, Joshi A, Sayami J. Pelvic organ prolapse in rural Nepalese women of reproductive age groups: what makes it so common? Nepal J Obstetr Gynaecol. 2007;2:35-41. https://doi.org/10. 3126/njog.v2i2.1453.

33. Akter F, Gartoulla P, Oldroyd J, Islam RM. Prevalence of, and risk factors for, symptomatic pelvic organ prolapse in rural Bangladesh: a cross-sectional survey study. Int Urogynecol J. 2016;27:1753-9. https://doi.org/10.1007/ s00192-016-3038-0.

34. Masenga GG, Shayo BC, Rasch V. Prevalence and risk factors for pelvic organ prolapse in Kilimanjaro, Tanzania: a population based study in Tanzanian rural community. PLoS One. 2018;13:e0195910. https://doi.org/10.1371/ journal.pone.0195910.

35. Abhyankar $\mathrm{P}$, Uny I, Semple $\mathrm{K}$, et al. Women's experiences of receiving care for pelvic organ prolapse: a qualitative study. BMC Womens Health. 2019; 191:45.

36. Chiaffarino F, Chatenoud L, Dindelli M, et al. Reproductive factors, family history, occupation and risk of urogenital prolapse. Eur J Obstet Gynecol Reprod Biol. 1999:82:63-7.

37. $\mathrm{MOH}$. Nepal demographic and health survey 2016. Kathmandu Nepal Minist heal Nepal; 2017.

38. Fotso JC, Cleland J, Mberu B, Mutua M, Elungata P. Birth spacing and child mortality: an analysis of prospective data from the Nairobi urban health and demographic surveillance system. J Biosoc Sci. 2013;45:779-98.

39. Karki YB. Sex preference and the value of sons and daughters in Nepal. Stud Fam Plann. 1988;19:169-78.

40. Mehata S, Paudel YR, Mehta R, Dariang M, Poudel P, Barnett S. Unmet need for family planning in Nepal during the first two years postpartum. Biomed Res Int. 2014;2014:649567. https://doi.org/10.1155/2014/649567 Epub 2014 Jun 5.

41. Rai P, Paudel IS, Ghimire A, et al. Effect of gender preference on fertility: cross-sectional study among women of Tharu community from rural area of eastern region of Nepal. Reprod Health. 2014;11:15. https://doi.org/10.1186/ 1742-4755-11-15.

\section{Publisher's Note}

Springer Nature remains neutral with regard to jurisdictional claims in published maps and institutional affiliations.

Ready to submit your research? Choose BMC and benefit from:

- fast, convenient online submission

- thorough peer review by experienced researchers in your field

- rapid publication on acceptance

- support for research data, including large and complex data types

- gold Open Access which fosters wider collaboration and increased citations

- maximum visibility for your research: over $100 \mathrm{M}$ website views per year

At $\mathrm{BMC}$, research is always in progress.

Learn more biomedcentral.com/submissions 